\title{
11. CURRENTS NEAR DEEP SEA DRILLING PROJECT HOLE 395A AND EFFECTS ON COMPONENTS OF THE MARINE SEISMIC SYSTEM PROJECT ${ }^{1}$
}

\author{
Janice Dinegar Boyd, Naval Ocean Research and Development Activity²
}

\begin{abstract}
Upper-level and near-bottom current measurements were made near Deep Sea Drilling Project Hole $395 \mathrm{~A}\left(22^{\circ} 45^{\prime} \mathrm{N}\right.$, $46^{\circ} 05^{\prime} \mathrm{W}$ ) in March and April 1981 in support of the at-sea test of the Marine Seismic System Project. Four upperocean current profiles were made during initial deployment of the borehole seismometer. Readings were noticeably contaminated by ship motion, but indicated a variable yet generally slow current regime that posed minimal threat of cable entanglement. Current measurements made $5 \mathrm{~m}$ off bottom during seismometer testing showed marked spectral peaks at semidiurnal and inertial frequencies. Mean speed of $4.4 \mathrm{~cm} / \mathrm{s}$ and maximum speed of $9 \mathrm{~cm} / \mathrm{s}$ were low but possibly of sufficient magnitude to cause contamination of concurrently deployed ocean bottom seismometer (OBS) records by hydrodynamically generated noise. Other studies have suggested noise contamination of OBS records by near-bottom currents, with a possible $10 \mathrm{~cm} / \mathrm{s}$ threshold for its importance. Although methods to detect and eliminate the noise might be developed, instrument testing and redesign to reduce sensitivity to contamination is probably more feasible.
\end{abstract}

\section{INTRODUCTION}

The first at-sea test of the Marine Seismic System (MSS) Project occurred in March and April 1981, during Leg 78B of the Deep Sea Drilling Project. Two types of physical oceanographic measurements were made at this time by NORDA (Naval Ocean Research and Development Activity) Code 331. Four profiles of ocean currents in the upper $1000 \mathrm{~m}$ were taken from the Lynch with a Neil Brown Instrument Systems (NBIS) Direct Reading Current Meter (DRCM) prior to and during deployment of the borehole seismometer. Completed profiles were transmitted immediately to the Challenger, where the data were used to orient the ship so as to avoid entanglement of the seismometer cable with the drill string. In addition, two Sea Link Systems' Vector Averaging Current Meters (VACM) were deployed approximately $5 \mathrm{~m}$ off bottom to help estimate hydrodynamic noise contamination of the records of concurrently deployed ocean bottom seismometers (OBS). Details of the VACM deployment are given in Table 1; positions of the VACMs, the operational OBS, and DSDP Hole 395A are shown in Figure 1. Positions of DRCM casts were within about $0.5 \mathrm{n}$. mi. of Hole 395A. This chapter summarizes the results of the DRCM casts and the two VACM deployments, comments on the DRCM results, and discusses the possibility of contamination of seismometer signals by hydrodynamic noise.

\section{BACKGROUND}

\section{Upper-Level Current Profiles}

The possibility of entanglement of the borehole seismometer cable with the drill string was a major concern during deployment of the seismometer package. Upper-

\footnotetext{
${ }^{1}$ Hyndman, R. D., Salisbury, M. H., et al., Init. Repts. DSDP, 78B: Washington (U.S. Govt, Printing Office).

2 Address: Naval Ocean Research and Development Activity, NSTL Station, MS 39529.
}

Table 1. Details of MSS current meter moorings near DSDP Hole 395A (Cruise Number: Lynch 070581).

\begin{tabular}{|c|c|c|c|}
\hline & & \multicolumn{2}{|c|}{ Mooring } \\
\hline & & 000901 & 001001 \\
\hline \multicolumn{2}{|c|}{ Position } & $\begin{array}{l}22^{\circ} 46.35^{\prime} \mathrm{N} \\
46^{\circ} 04.59^{\prime} \mathrm{W}\end{array}$ & $\begin{array}{l}22^{\circ} 46.10^{\prime} \mathrm{N} \\
46^{\circ} 05.49^{\prime} \mathrm{W}\end{array}$ \\
\hline Dates $^{a}$ & $\begin{array}{l}\text { From } \\
\text { To }\end{array}$ & $\begin{array}{l}1526 Z \\
28 \text { March } 1981 \\
0837 Z \\
1 \text { April } 1981\end{array}$ & $\begin{array}{l}1814 Z \\
28 \text { March } 1981 \\
0837 Z \\
1 \text { April } 1981\end{array}$ \\
\hline \multicolumn{2}{|c|}{ Water depth (m) } & 4483 & 4483 \\
\hline \multicolumn{2}{|c|}{ Meter depth (m) } & 4478 & 4478 \\
\hline \multicolumn{2}{|c|}{ Sampling rate (s) } & 56 & 56 \\
\hline \multicolumn{2}{|c|}{ Meter number } & 289 & 300 \\
\hline \multicolumn{2}{|c|}{ Performance } & Very good & Satisfactory \\
\hline
\end{tabular}

level current measurements were needed during the deployment in order to orient the Challenger so as to keep the cable downstream of the drill string and thus reduce the risk of entanglement. Equipment suitable for making accurate real-time current measurements deeper than a few hundred meters was (and is) limited. The NBIS Direct Reading Current Meter selected (underwater unit Model DRCM-1, deck unit CMDT-1) was a new, readily available but relatively untested instrument; however, it did use previously developed and proven technology.

\section{Hydrodynamically Generated Noise}

Some results have shown near-bottom currents can produce noise contamination in ocean-bottom seismometer (OBS) records (Sutton et al., 1981, Duennebier et al., 1981). One aspect of the Lopez Island OBS intercomparison experiment (Sutton et al., 1981) was to examine sensitivity of different OBS systems to contamination from hydrodynamically generated noise. Results were incon- 


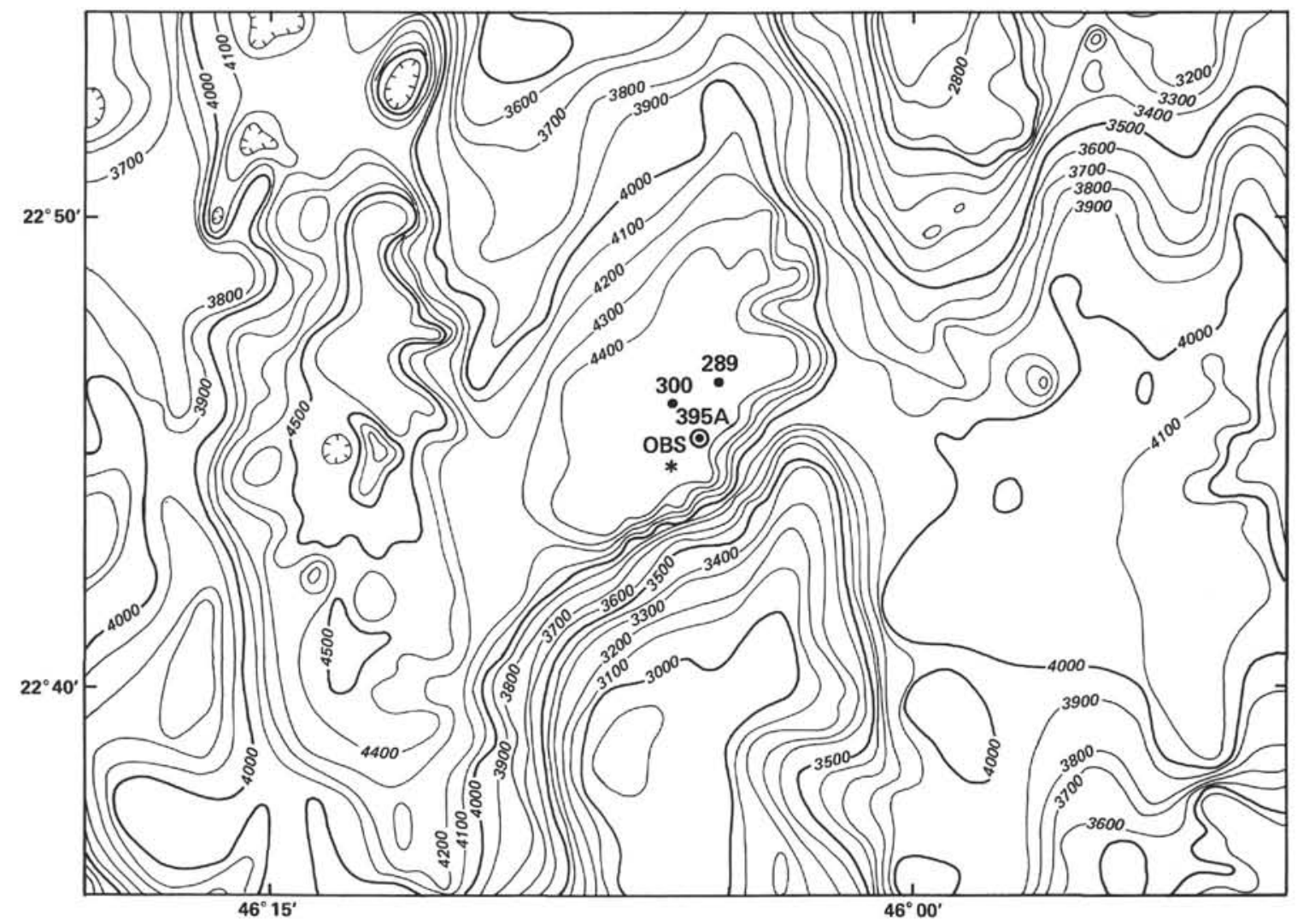

Figure 1. Locations of Current Meters 289 and 300, of Hole 395A, and of the operational OBS during March and April 1981 MSS at-sea test (from Hussong et al., 1979; depth is in meters).

clusive, but current speeds were low, a maximum of 6 $\mathrm{cm} / \mathrm{s}$. Mean currents near DSDP Hole 395A were anticipated to be low (Wilcox, 1978), but there were no direct observations from the site. Because hydrodynamically induced noise is generally recognized as a possible problem with OBSs, a knowledge of currents near the site could be valuable in identifying the sources of anomalous signals should they show up in the seismic records of the OBSs or borehole seismometer.

Currents can generate noise in seismic records in three ways. The first occurs when the fluid motion is highly turbulent. (The drag and lift forces exerted on an instrument by the fluctuating flow may cause small motions or vibrations of the object that are recorded as noise.) The second occurs when current-generated noise is transmitted through the bottom and picked up by the instrument. (The noise may occur when random pressure fluctuations of the turbulent boundary layer actually disturb the bottom sediments or nearby equipment may be disturbed by the turbulent flow, with the motion being transmitted through the bottom.) Under the low current speeds expected near Hole 395A, these sources of noise are unlikely to be as important as the third mechanism: vortex shedding from objects in the flow.

The character of fluid flow past an object is largely determined by the Reynolds number, $R e$, defined as

$$
\operatorname{Re}=\frac{U \cdot d}{\nu}
$$

where $U$ is a characteristic speed of the flow; $d$, a characteristic dimension of the object; and $\nu$ the kinematic viscosity. At low $R e$ the fluid flow closely follows the contours of the body, but above a critical $R e$ the boundary layer separates from the body and forms a turbulent wake. Up to a certain maximum $R e$ the separation for some body shapes occurs nearly periodically in the form of shedding of pairs of alternate-sense vortices. Separation and wake formation causes a reduced pressure gradient in the lee of the object, particularly on the side from which a vortex is shed. The shedding of oppositesense vortices in a wake produces nearly periodic forces on the body at the shedding frequency $f_{s}$. This is the source of aeolian tones caused by wind over wires under tension and the "strumming" of hydrographic cables during CTD (conductivity, temperature, and depth) casts. For cylindrical bodies normal to the flow and for $40<$ $R e<4 \times 10^{5}$ this frequency is given by

$$
f_{s}=\frac{U \cdot S}{d}
$$

where $S$ is the Strouhal number (Batchelor, 1967). (There is some dependence on geometry and turbulence level of the free stream, but this gives $f_{s}$ well within an order of magnitude.) For $R e>200$, the Strouhal number is nearly a constant 0.2 (Every et al., 1982).

The sensitive range of many contemporary seismometers-0.01-30.0 Hz (R. Jacobson, personal communi- 
cation, 1981)-includes the range of shedding frequencies due to currents that one would expect to encounter in the deep ocean. In his summary of deep ocean current speeds, Wilcox (1978) found a mean deep current speed in the eastern Atlantic of about $5 \mathrm{~cm} / \mathrm{s}$. For a 1 -in. cable this translates into a shedding frequency of about $0.4 \mathrm{~Hz}$. Thus there is the potential for the contamination of seismometer readings by noise from turbulent eddy shedding.

\section{MEASUREMENTS}

The NBIS Direct Reading Current Meter selected for the upper-level current profiles had a specified speed accuracy of $\pm 1 \mathrm{~cm} / \mathrm{s}$ or $5 \%$ (whichever is greater). Direction accuracy was $\pm 5^{\circ}$ for speeds greater than $10 \mathrm{~cm} / \mathrm{s}$. Pressure was accurate to \pm 1.0 decibar and precise to \pm 0.05 decibar (A. W. Green, personal communication, 1981). One-minute vector averages of speed and direction were recorded, and pressure was periodically checked to provide depth values.

Near-bottom measurements were taken with Sea Link Systems' Vector Averaging Current Meters (Model 610), which recorded average speed, east and north velocity components, direction and temperature every 0.9375 min. Speed was accurate to $\pm 1 \mathrm{~cm} / \mathrm{s}$ or better, and the threshold of the Savonious rotor was $3 \mathrm{~cm} / \mathrm{s}$ or lower. Direction was accurate to $\pm 3^{\circ}$. The installed thermistors were accurate to $\pm 0.1^{\circ} \mathrm{C}$ and precise to $\pm 0.01^{\circ} \mathrm{C}$. The manufacturer's manual (AMF, 1976) gives further details on instrument construction, and Woodward and Appel (1973) and McCullough (1975) describe calibration of the instrument. The mechanical rotor of the VACM tends to stall at low current speeds and to behave in a nonlinear manner, so the VACM was not the optimal instrument for the low currents anticipated. However, it was the only meter type available with a pressure casing suitable for the $4500-\mathrm{m}$ depth. In spite of current speeds near rotor-stall speed, the two instruments performed adequately.

\section{PRESENTATION OF DATA}

\section{Upper-Level Current Profiles}

Four velocity profiles taken with the DRCM during the seismometer deployment are shown in Figure 2. Profiling was terminated by a seal failure at the end of Cast 4 or beginning of Cast 5. With the exception of currents in the upper $100 \mathrm{~m}$ during the first cast, current speeds were low (below $20 \mathrm{~cm} / \mathrm{s}$ ) and directions variable.

The unknown time of failure precludes a strict evaluation of the quality of the profile data. There are considerable differences between profiles. In particular, the first cast showed substantially higher current speeds than succeeding casts. However, ship's radar fixes on the Challenger taken by Lynch personnel every $20 \mathrm{~min}$. during the profiling indicated a drift of $1 / 3-1 / 2$ knots $(\approx 20$ $\mathrm{cm} / \mathrm{s}$ ) to the northeast during the first cast, a larger drift than at any other time during the profiling. (A considerable wire angle was also noted at this time.) The higher observed values for this profile may indeed be correct, due to wind- or surface-current-induced ship motion or to a transient, highly energetic current regime.

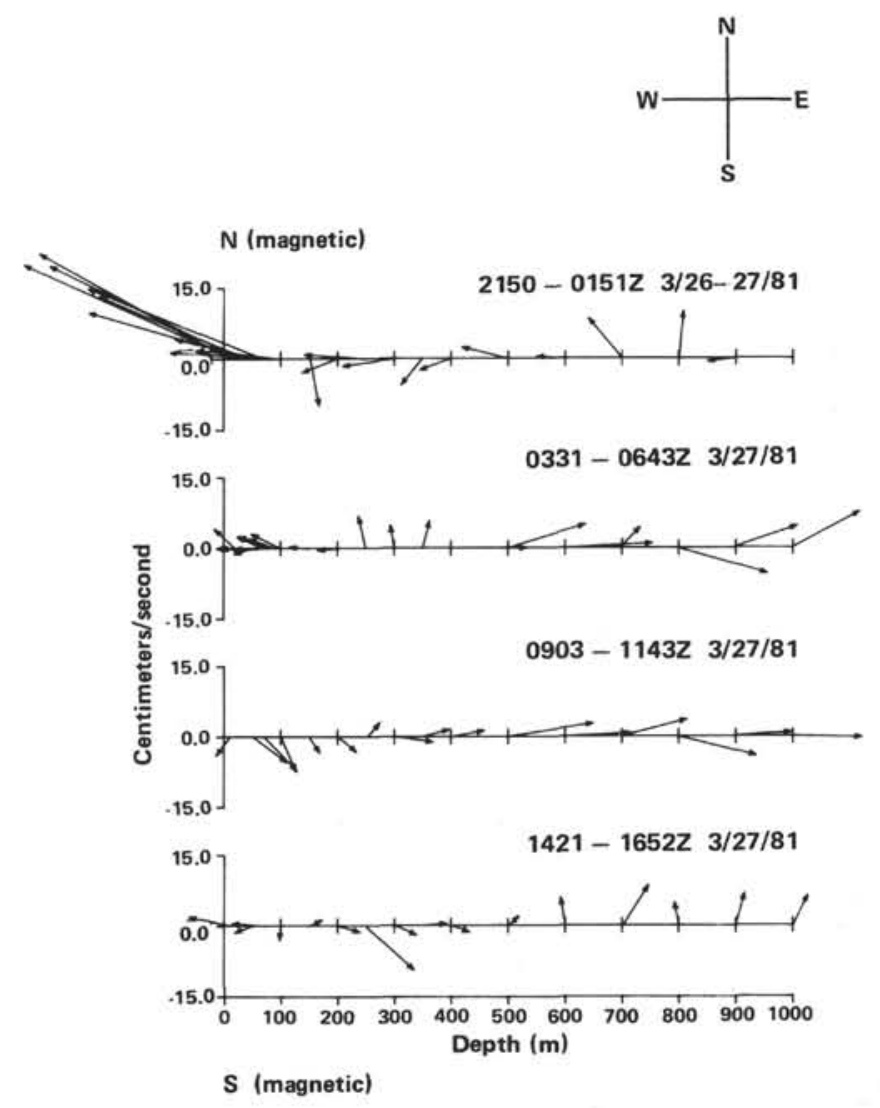

Figure 2. Currents (cm/s) in upper $1000 \mathrm{~m}$ near Hole 395A during deployment of borehole seismometer. Length and direction of each arrow corresponds to speed and direction of the current at the indicated depth.

Ship motion affected the DRCM readings at other times. During periods of swell when the Lynch rolled substantially, the pressure values commonly indicated vertical excursions of more than \pm 5 decibar (equivalent to $\pm 5 \mathrm{~m}$ ). When the wire from the hydrographic winch rotated about a vertical axis (making a circle in a horizontal plane), instantaneous direction measurements often changed rapidly and monotonically.

The purpose of the DRCM was to furnish approximate $( \pm 20 \mathrm{~cm} / \mathrm{s})$ upper bounds for the currents, and it appears that the DRCM and deck unit satisfied these requirements until the end of Cast 4 or the beginning of Cast 5 . However, the measurements were contaminated by ship motion. It was known from the beginning that ship motion would affect the DRCM data, but neither time nor resources were available to compensate for the motion.

\section{Near-Bottom Current and Temperature-Time Series and Data Editing}

The near-bottom velocities were first plotted as time series. Each record was examined for anomalous data. Records were discarded for those times the meters were not in position near the bottom. Meter 289 performed well. Occasional isolated spikes were replaced with linearly interpolated values. The corrected series for Meter 289 is given in Figure 3. Meter 300 performed satisfacto- 

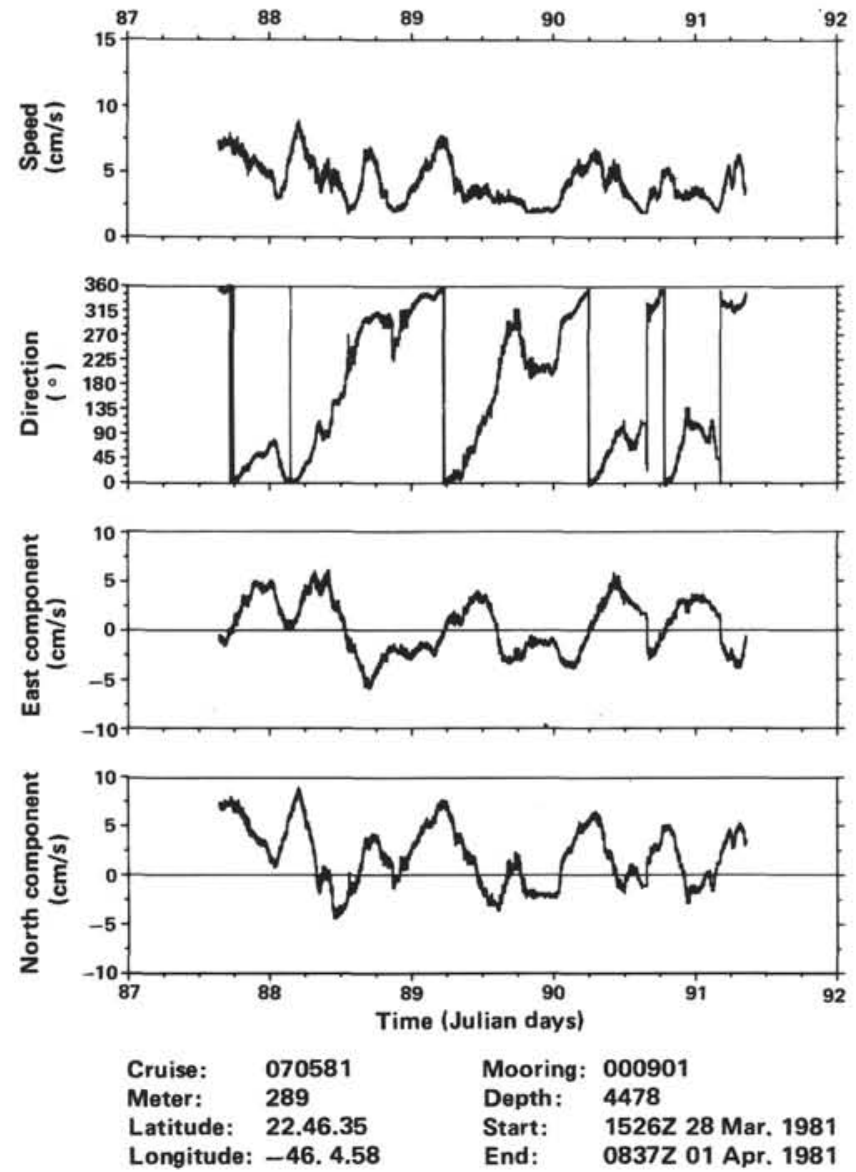

Figure 3. Meter 289 current time series. Direction is from magnetic north.

rily in view of the very low current speeds encountered, but had a higher stalling threshold than Meter 289, as seen in Figure 4. Superposition of Figures 3 and 4 shows, however, that when Meter 300 was not stalled the measured current speeds and directions for both were quite similar. Current speeds tended to be low (below $10 \mathrm{~cm} / \mathrm{s}$ ), with minor high frequency fluctuations superimposed upon a very distinct periodicity of about 2 cpd (cycles per day) (presumably the semidiurnal tide). Direction changed continuously with a period somewhat greater than 1 day (presumably inertial oscillations or the diurnal tide). These motions were confirmed by spectral analysis, which showed considerable energy at the inertial-diurnal (given our frequency resolution, they are too close to be well resolved: 31-hr. period versus 23.9-hr. period) and semidiurnal frequencies. Temperature was nearly constant at about $2.4^{\circ} \mathrm{C}$ (in situ), as would be expected for the anticipated North Atlantic Bottom Water (NAVOCEANO, 1966; and Fleischer, 1980).

\section{Near-Bottom Current Statistics}

The basic current statistics are summarized in Table 2 . Only Meter 289 provided a reliable estimate of average speed, because Meter 300 tended to stall at low speeds. Average scalar speed for Meter 289 was $4.4 \mathrm{~cm} / \mathrm{s}$ and vector mean speed was $2.1 \mathrm{~cm} / \mathrm{s}$ in a direction of $\mathrm{N} 12^{\circ} \mathrm{E}$.
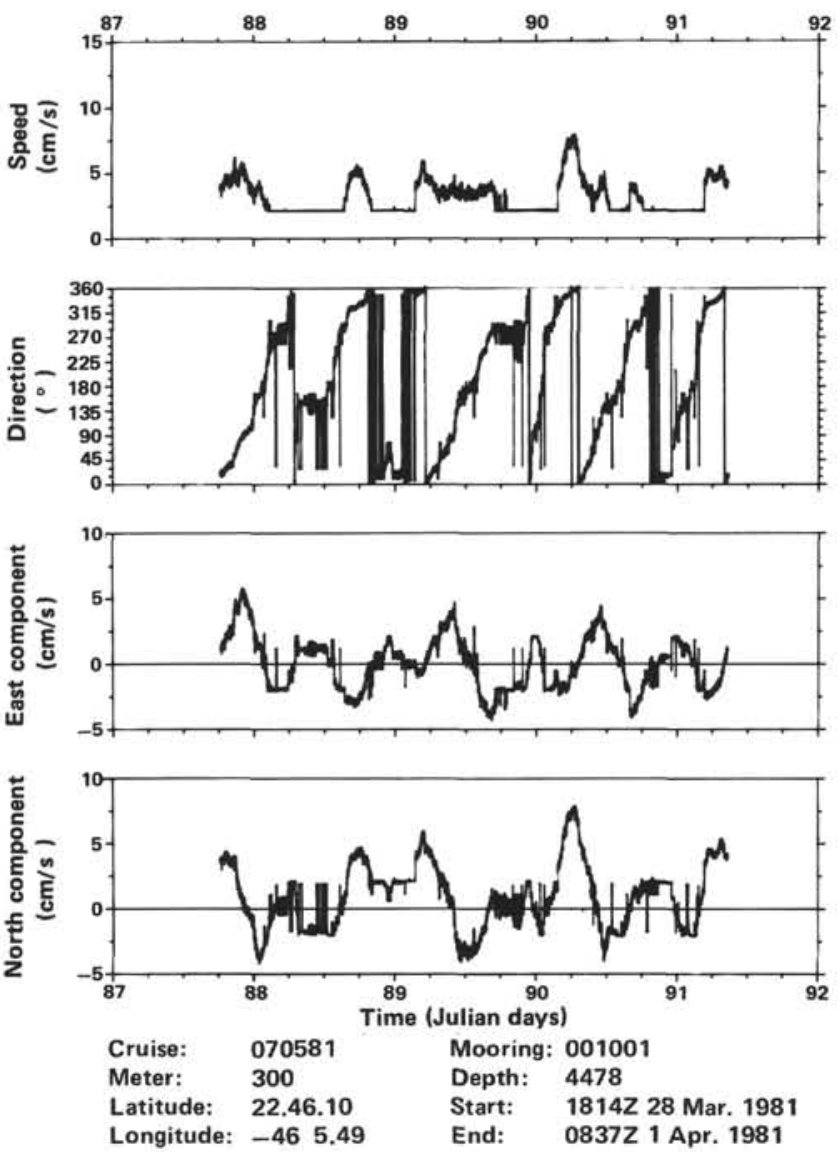

Figure 4. Meter 300 current time series. Direction is from magnetic north.

Table 2. Basic current statistics for Meters 289 and 300.

\begin{tabular}{lrr}
\hline & Meter 289 & Meter 300 \\
\hline Scalar mean speed $(\mathrm{cm} / \mathrm{s})$ & 4.4 & 3.1 \\
Standard deviation of scalar mean speed $(\mathrm{cm} / \mathrm{s})$ & 1.6 & 1.3 \\
Maximum speed $(\mathrm{cm} / \mathrm{s})$ & 8.9 & 7.9 \\
Direction of maximum speed $\left({ }^{\circ}\right)$ & 9.8 & 358.0 \\
Vector mean speed $(\mathrm{cm} / \mathrm{s})$ & 2.1 & 0.9 \\
Vector mean direction $\left({ }^{\circ}\right)$ & 11.6 & 357.5 \\
Maximum east component $(\mathrm{cm} / \mathrm{s})$ & 6.1 & 5.7 \\
Minimum east component $(\mathrm{cm} / \mathrm{s})$ & -6.1 & -4.3 \\
Maximum north component $(\mathrm{cm} / \mathrm{s})$ & 8.8 & 7.9 \\
Minimum north component $(\mathrm{cm} / \mathrm{s})$ & -4.5 & -4.2 \\
\hline
\end{tabular}

Maximum speed for Meters 289 and 300 were 8.9 and $7.9 \mathrm{~cm} / \mathrm{s}$, respectively.

\section{Near-Bottom Current Spectra}

The east-north and clockwise-counterclockwise velocity spectra are presented in Figures 5 and 6 . Annotations indicate the periods of a number of conspicious peaks.

In spite of the short (3.3-day) record length, peaks near diurnal and semidiurnal periods are quite distinct. The inertial period of $31 \mathrm{hr}$. is close to the $K_{1}$, or diurnal tidal peak (23.93 hr.). However, the near-diurnal peak is probably due largely to inertial currents, for two 
A

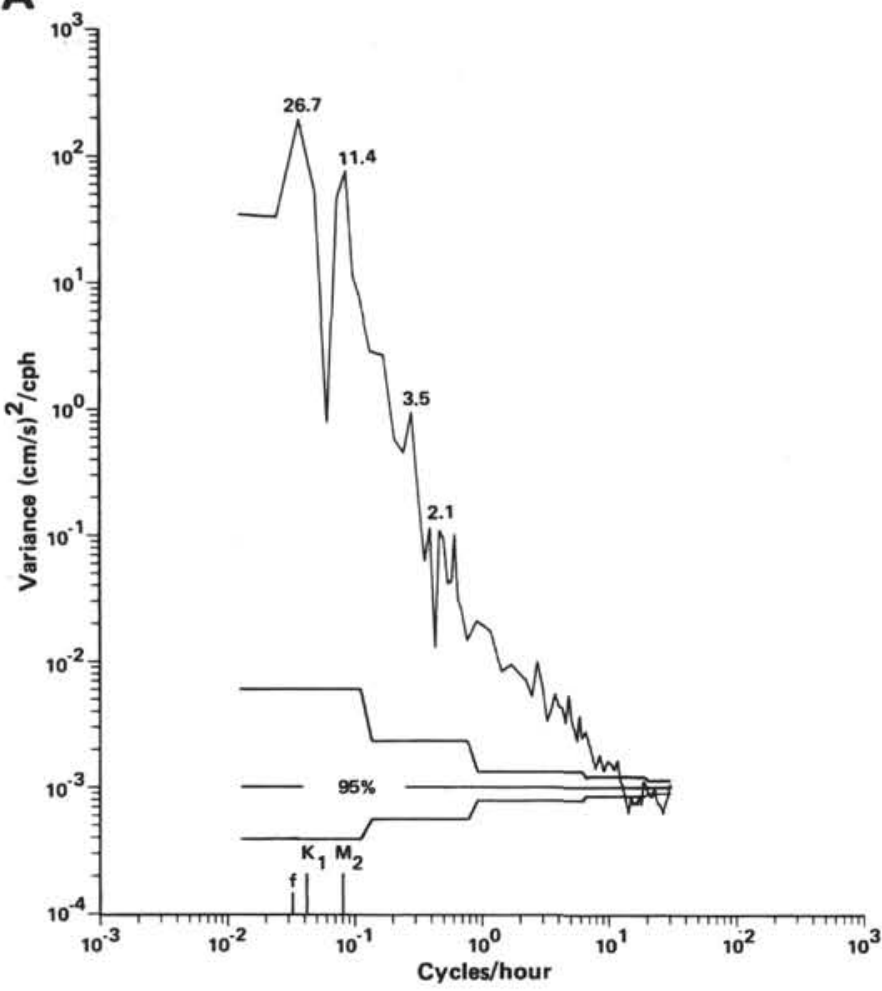

B

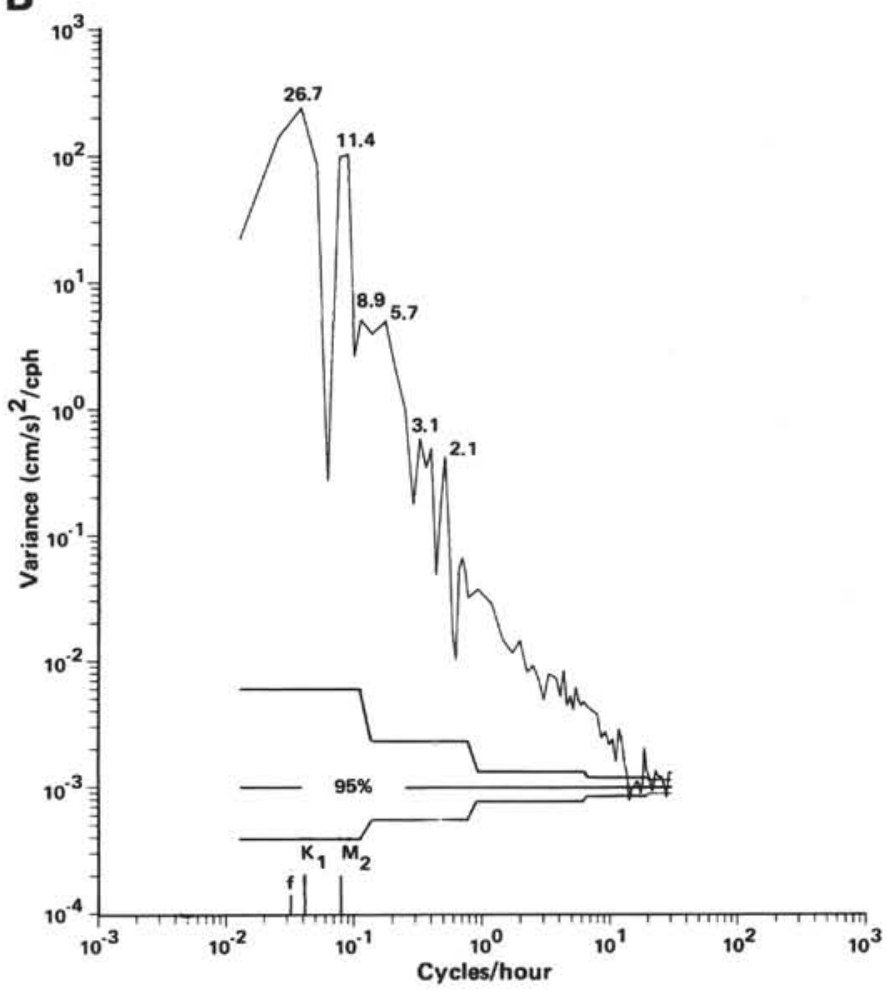

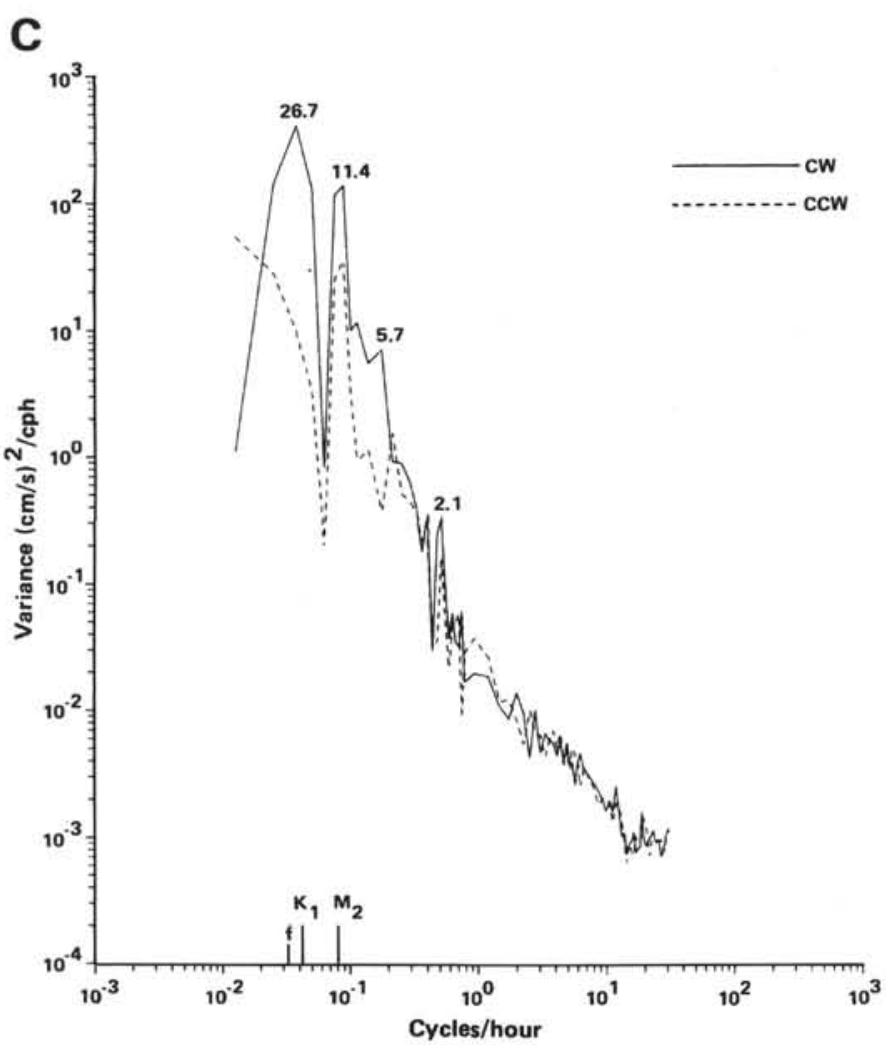

Figure 5. Meter 289 current spectra. A. East component. B. North component. C. Rotary components. (CW $=$ clockwise; $\mathrm{CCW}=$ counterclockwise; $\mathrm{cph}=$ cycles per hour. See text for explanations of $\mathrm{K}_{1}$ and $\mathrm{M}_{2}$.) 

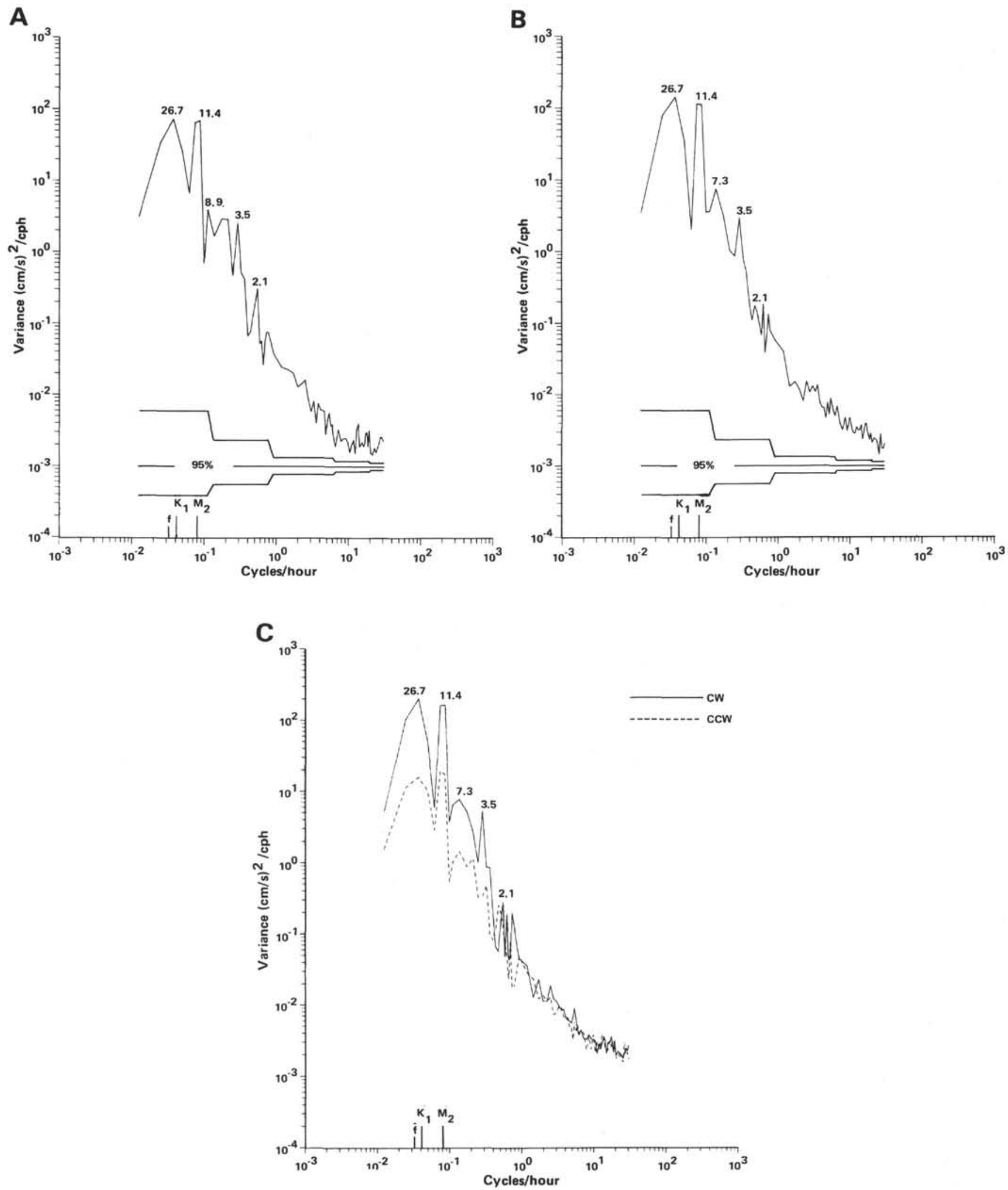

Figure 6. Meter 300 current spectra. A. East component. B. North component. C. Rotary components. $(\mathrm{CW}=$ clockwise; $\mathrm{CCW}=$ counterclockwise; $\mathrm{cph}=$ cycles per hour. See text for explanation of $\mathrm{K}_{1}$ and $\mathbf{M}_{2}$.) 
reasons. First, near the diurnal peak the clockwise rotary spectral components are much larger than the counterclockwise. Second, the east and north velocity spectra at that frequency are of nearly equal magnitude. Although these criteria are not sufficient to unequivocally identify inertial oscillations, they are necessary characteristics that northern hemisphere inertial oscillations must possess. If the motions are indeed primarily inertial oscillations, they may be episodic, their occurrence in a given record depending upon the presence of a forcing phenomenon.

A second prominent spectral peak occurs near the semidiurnal tidal period of $12.42 \mathrm{hr}$. and is probably the $\mathrm{M}_{2}$ tide. Tidal signals in the open ocean are frequently not this energetic relative to the rest of the spectrum, and this peak may reflect the influence of the nearby topography and the absence of other forcing phenomena as well.

Temperature spectra (not plotted) show virtually no variation, and in particular there is no evidence of any diurnal or semidiurnal periodicity.

\section{SUMMARY AND CONCLUSIONS}

Real-time current profiles were taken near DSDP Hole 395A on 26 to 27 March 1981 from the Lynch with an NBIS Direct Reading Current Meter. The profiling was done during the initial deployment of the Marine Seismic System Project's borehole seismometer from the Glomar Challenger. Readings indicated a variable but generally slow current regime (below $20 \mathrm{~cm} / \mathrm{s}$ ) during the profiling period. Sea-state conditions 0 or 1 prevailed during the profiling. Nevertheless, significant contamination of the records by ship motion was apparent, and deployment from the Challenger would have been preferable. Unless techniques are applied to decouple the profiler from the ship's motion, it appears inadvisable to deploy the DRCM from a platform as unstable as many research vessels above sea state 1 or 2 . For higher sea state, satisfactory results could be expected only when the current regime is sufficiently energetic that noise induced by ship motion does not mask the background current measurements, although the accuracy of the measurements would still be reduced. In spite of the ship-motion contamination, however, observed current speeds in the upper $1000 \mathrm{~m}$ were shown to be generally low and to pose minimal threat of cable entanglement. It should be noted, though, that mesoscale features such as eddies or inertial oscillations could cause a radically different regime at other times.

Sea Link Vector Averaging Current Meters deployed near the bottom in $4483 \mathrm{~m}$ of water for 3.5 days in March and April 1981 performed satisfactorily under conditions of very low current speeds. Average (scalar) speed was $4.4 \mathrm{~cm} / \mathrm{s}$, and maximum speed was under $9 \mathrm{~cm} / \mathrm{s}$. The mean direction of flow was slightly east of north, with a steady clockwise rotating component of period somewhat greater than one day superimposed on the mean flow. The rotating component is attributed to inertial oscillations. The semidiurnal tide was also apparent and at a sufficiently energetic level that topographic forcing may be important. Temperature was constant at $2.4^{\circ} \mathrm{C}$ (in situ).

The observed currents were of sufficient magnitude potentially to excite instrument "strumming" due to vortex shedding at frequencies within the sensitive range of contemporary ocean bottom seismometers $(0.01-30 \mathrm{~Hz}$; see Table 3). Figure 7 shows estimated vortex-shedding frequencies for four sizes of cylinders for currents in the range of the current meter observations. The complicated geometries of the OBSs make it difficult to isolate any particular components that might be likely to contribute to strumming noise except perhaps for the radio beacon antennas. Assuming an antenna rod thickness of $1 / 8 \mathrm{in}$., the strumming frequency would be $6 \mathrm{~Hz}$ at $9 \mathrm{~cm} / \mathrm{s}$ and $3 \mathrm{~Hz}$ at $4.4 \mathrm{~cm} / \mathrm{s}$. If this frequency were near

Table 3. Diameters of cylindrical bodies that would oscillate at the extrema of the OBS frequency range under mean and maximum current conditions observed.

\begin{tabular}{ccc}
\hline & \multicolumn{2}{c}{ Diameter $(\mathrm{cm})$} \\
\cline { 2 - 3 } $\begin{array}{c}\text { Frequency } \\
(\mathrm{Hz})\end{array}$ & $\begin{array}{c}\text { Mean speed }= \\
4.4 \mathrm{~cm} / \mathrm{s}\end{array}$ & $\begin{array}{c}\text { Maximum speed }= \\
9 \mathrm{~cm} / \mathrm{s}\end{array}$ \\
\hline 0.01 & 0.011 & 0.0056 \\
30 & 34.1 & 16.67 \\
\hline
\end{tabular}

Note: Applicable formula

$d=\frac{f_{S}}{0.2 \cdot U}$

where $d=$ object diameter, $f_{S}=$ frequency, and $U=$ current speed.

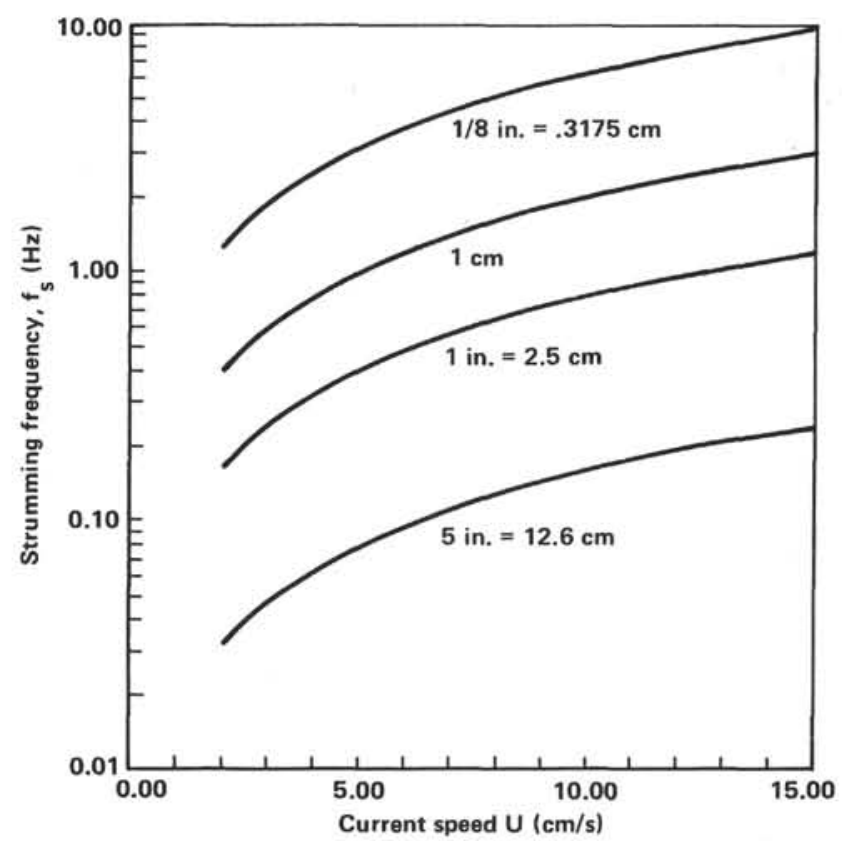

Figure 7. Strumming frequency versus current speed for cylindrical bodies of various diameters in flows of Reynolds number $2 \times 10^{2}$ to $4 \times 10^{5}$. 
a resonant frequency of the rod or of the attached flag, strumming amplitude could be substantial. Duennebier et al. (1981) did report noise signals in OBS recordings that could be attributed to vortex shedding from various antenna configurations.

As reported by Duennebier et al. (1981), Japanese researchers found $10 \mathrm{~cm} / \mathrm{s}$ to be a lower threshold for noise contamination by vortex shedding. Maximum currents in this study were $9 \mathrm{~cm} / \mathrm{s}$, suggesting that contamination of these OBS records is likely to be small and intermittent. But Figures 2 and 3 illustrate that deep-water, nearbottom current regimes are characterized by considerable variability in speed and direction. Internal tides, inertial oscillations, and other phenomena make it a mistake to assume that the operating environment of a deep-water OBS will be characterized by steady, slow currents. The variable and possibly episodic nature of these current features can make it difficult to detect and remove noise contamination. The development of methods of evaluating noise contamination of seismometer records is recommended. Also, OBSs should be tested for sensitivity to current-generated noise and redesigned to eliminate this sensitivity as much as possible.

One approach to evaluating noise contributions from vortex shedding would be to compute for each external OBS component a time series of shedding frequency from the observed current time series. Coherence between OBS signal level and the shedding frequency time series could give an indication of the current's influence. Such a technique could also be applied to the borehole seismometer and related hardware if it were felt that the instrument might be influenced by vortex shedding off components on the bottom.

A better approach, particularly in view of the complicated geometry of OBS systems and the difficulty and expense of making current measurements, is noise sensitivity evaluation and instrument redesign. To evaluate the response at different fluid speeds the instrument could be placed in a tank or wind tunnel, and the equipment either moved through the fluid or the fluid moved past it and the pure noise signal recorded. A very important point is that the fluid could be air rather than water, if proper Reynolds' scaling were observed.

This study, as well as others, shows there is potential for OBS observational data to be contaminated by hydrodynamically generated noise. Up to now investigation of the importance of the problem has been neglected, but methods of evaluating the magnitude of the problem for various OBS designs and of solving it, should it prove significant, should be addressed in the future.

\section{ACKNOWLEDGMENTS}

This work was possible only with the fine assistance of the officers and crew of the Lynch, E. Maier commanding. Special thanks goes to Lou Banchero and Steve Sova who repaired, checked out, deployed, recovered, and otherwise cared for the equipment used. Program managers Al Ballard and Mike Harris fulfilled their responsibilities with tact, understanding, and, in several cases, great creativity and persistence. I am indebted to Dr. Albert Green for valuable discussions and guidance, to Mike Stirgus for much computing assistance, and to Joyce Ford for secretarial services. The work was partially funded by NORDA Code 543 contract D3311A00. Most of these findings are also presented in the final report for that contract, NORDA Technical Note 132. This chapter is NORDA Contribution 331:035:82.

\section{REFERENCES}

AMF, 1976. Vector Averaging Current Meter, Model 610C. AMF Electrical Products Development Division of AMF Incorporated, Herndon, Virginia.

Batchelor, G. K., 1967. An Introduction to Fluid Dynamics: Cambridge, England (Cambridge University Press), p. 216.

Duennebier, F. K., Blackinton, G., and Sutton, G. H., 1981. Currentgenerated noise recorded on ocean bottom seismometers. Mar. Geophys. Res., 5(1):109-115.

Every, M. J., King, R., and Weaver, D. S., 1982. Vortex-excited vibrations of cylinders and cables and their suppression. Ocean Engng., 9(2):135-157.

Fleischer, P., 1980. Weather and currents in the vicinity of $23^{\circ} \mathrm{N}, 46^{\circ} \mathrm{W}$, North Atlantic Ocean. NORDA Tech. Note 74, NORDA, NSTL Station, Mississippi.

Hussong, D. M., Fryer, P. B., Tuthill, J. D., and Wipperman, L. K., 1979. The geological and geophysical setting near DSDP Site 395 , North Atlantic Ocean. In Melson, W. G., Rabinowitz, P. D., et al., Init. Repts. DSDP, 45: Washington (U.S. Govt. Printing Office), 23-37.

McCullough, J. R., 1975. Vector Averaging Current Meter speed calibration and recording procedure. Woods Hole Oceanographic Institution Tech. Rept., WHOI-75-44.

NAVOCEANO, 1966. Handbook of Oceanographic Tables: Washington (U.S. Naval Oceanographic Office).

Sutton, G. H., Lewis, B. T. R., Ewing, J., Duennebier, F. K., Iwatake, B., and Tuthill, J. D., 1981. An overview and general results of the Lopez Island OBS experiment. Mar. Geophys. Res., 5(1):3-34.

Wilcox, J. D., 1978. A survey of current speed measurements in the deep ocean. NUSC Tech. Mem. 781176: Newport, R. I., and New London, Conn. (Naval Underwater Systems Center).

Woodward, W. E., and Appell, G. F., 1973. Report on the evaluation of a Vector Averaging Current Meter. NOAA Tech. Memo. NOAATM-NOS-NOIC-1.

Date of Initial Receipt: August 11, 1982

Date of Acceptance: April 26, 1983 